\title{
CaMKII Modulates Diacylglycerol Lipase- $\alpha$ Activity in the Rat Nucleus Accumbens after Incubation of Cocaine Craving
}

\author{
Conor H. Murray, ${ }^{1,2}$ Andrew D. Gaulden, ${ }^{3}$ Alex B. Kawa, ${ }^{2}$ Mike Milovanovic, ${ }^{1}$ Aaron J. Caccamise, ${ }^{1}$ \\ Jonathan R. Funke, ${ }^{2}$ Sachin Patel, ${ }^{3}$ and ${ }^{-}$Marina E. Wolf ${ }^{1,2}$
}

https://doi.org/10.1523/ENEURO.0220-21.2021

${ }^{1}$ Department of Neuroscience, Chicago Medical School, Rosalind Franklin University of Medicine and Science, North Chicago, Illinois 60064-3095, ${ }^{2}$ Department of Behavioral Neuroscience, Oregon Health \& Science University, Portland, Oregon 97239-3098, and ${ }^{3}$ Department of Psychiatry, Vanderbilt University, Nashville, Tennessee 37240

\begin{abstract}
Relapse is a major challenge to the treatment of substance use disorders. A progressive increase in cue-induced drug craving, termed incubation of craving, is observed after withdrawal from multiple drugs of abuse in humans and rodents. Incubation of cocaine craving involves the strengthening of excitatory synapses onto nucleus accumbens (NAc) medium spiny neurons via postsynaptic accumulation of high-conductance $\mathrm{Ca}^{2+}$-permeable AMPA receptors. This enhances reactivity to drug-associated cues and is required for the expression of incubation. Additionally, incubation of cocaine craving is associated with loss of the synaptic depression normally triggered by stimulation of metabotropic glutamate receptor 5 (mGlu5), leading to endocannabinoid production, and expressed presynaptically via cannabinoid receptor 1 activation. Previous studies have found alterations in mGlu5 and Homer proteins associated with the loss of this synaptic depression. Here we conducted coimmunoprecipitation studies to investigate associations of diacylglycerol lipase- $\alpha$ (DGL), which catalyzes formation of the endocannabinoid 2-arachidonylglycerol (2-AG), with mGlu5 and Homer proteins. Although these interactions were unchanged in the NAc core at incubation-relevant withdrawal times, the association of DGL with total and phosphorylated $\mathrm{Ca}^{2+} /$ calmodulin-dependent protein kinase Il $\alpha$ (CaMKIl $\alpha$ ) and CaMKII $\beta$ was increased. This would be predicted, based on other studies, to inhibit DGL activity and therefore 2-AG production. This was confirmed by measuring DGL enzymatic activity. However, the magnitude of DGL inhibition did not correlate with the magnitude of incubation of craving for individual rats. These results suggest that CaMKII contributes to the loss of mGlu5-dependent synaptic depression after incubation, but the functional significance of this loss remains unclear.
\end{abstract}

Key words: CaMKII; cocaine; diacylglycerol lipase; incubation of craving

\section{Significance Statement}

Cue-induced drug craving progressively intensifies or incubates after withdrawal from extended-access drug selfadministration, augmenting relapse vulnerability. Incubation of cocaine craving in rats is accompanied by robust plasticity in the NAc, including strengthening of excitatory synapses via postsynaptic AMPAR plasticity and the loss of endocannabinoid-dependent synaptic depression. Our results identify a novel mechanism that may account for this loss of synaptic depression, namely reduced activity of DGL, the enzyme that produces the endocannabinoid 2-AG, along with increased physical association of this enzyme with CaMKIl, an association predicted to reduce the enzymatic activity of DGL. These findings expand our understanding of mechanisms underlying cocaine-induced alterations in endocannabinoid-dependent synaptic depression.

Received May 3, 2021; accepted August 19, 2021; First published September 20, 2021.

The authors declare no competing financial interests.
Author contributions: C.H.M., S.P., and M.E.W. designed research; C.H.M., A.D.G., A.B.K., M.M., A.J.C., and J.R.F. performed research; C.H.M. and A.D. G. analyzed data; C.H.M. and M.E.W. wrote the paper. 


\section{Introduction}

Relapse is often triggered by exposure to drug-associated cues even after prolonged abstinence (O'Brien, 2005). During abstinence, cue-induced craving intensifies over time, a phenomenon termed incubation of craving. Incubation of cocaine craving has been well documented in rats (Pickens et al., 2011) and also studied in humans (Parvaz et al., 2016), where cue-induced craving peaks between 1 and 6 months before declining by 1 year of abstinence. This trajectory is similar in rats, where craving is maximal after $\sim 1$ month, remains high for months, and then declines, although it remains significantly elevated, compared with withdrawal day 1 (WD1), after $180 \mathrm{~d}$ (Lu et al., 2004).

Incubation involves adaptations in regions related to motivation and reward including the nucleus accumbens (NAc; Li et al., 2015; Wolf, 2016; Wright and Dong, 2020). The NAc serves as an interface between cortical and limbic inputs and motor-related outputs, thereby contributing to the execution of motivated behaviors (Meredith et al., 2008; Sesack and Grace, 2010). Medium spiny neurons (MSNs), the principal cell type and projection neurons of the NAc, receive glutamatergic projections from cortical and limbic regions. Incubation of cocaine craving is associated with the incorporation of high-conductance calcium-permeable AMPA receptors (CP-AMPARs) into excitatory synapses of NAc core and shell MSNs (Wolf, 2016). In the core, this begins after $\sim 1$ month of withdrawal (Wolf and Tseng, 2012). Once present, CPAMPAR activation is required for the expression of incubation (Conrad et al., 2008; Lee et al., 2013; Loweth et al., 2014; Ma et al., 2014). It is theoretically possible that the expression of incubation also involves a reduction in mechanisms that normally constrain excitatory transmission in the NAc, such as long-term depression (LTD).

A well characterized form of LTD in the NAc is triggered by metabotropic glutamate receptor 5 (mGlu5), leading to the generation of endocannabinoids (eCBs) that act as retrograde messengers to stimulate presynaptic cannabinoid receptor 1 (CB1R), resulting in the reduction of glutamate release from excitatory afferents in the NAc (Robbe et al., 2001, 2002; Zlebnik and Cheer, 2016; Araque et al., 2017; Augustin and Lovinger, 2018). The best characterized eCB ligands are anandamide (AEA)

This work was supported by National Institutes of Health Grants DA-009621 and DA-015835 (M.E.W.), F32-DA-050457 (A.B.K.), and MH-107435 (S.P.)].

C.H. Murray's present address: Department of Psychiatry and Biobehavioral Sciences, University of California, Los Angeles, Los Angeles, CA 90095.

A.D. Gaulden's present address: Neuroscience Graduate Program, University of Cincinnati, Cincinnati, $\mathrm{OH} 45267$

A.J. Caccamise's present address: Department of Biomedical Sciences, Marquette University, Milwaukee, WI 53304.

Acknowledgements: We thank Dr. Ken Mackie at Indiana University, Bloomington, for supplying the DGL- $\alpha$ antibody.

Correspondence should be addressed to Marina E. Wolf at wolfmar@ohsu. edu.

https://doi.org/10.1523/ENEURO.0220-21.2021

Copyright (C) 2021 Murray et al.

This is an open-access article distributed under the terms of the Creative Commons Attribution 4.0 International license, which permits unrestricted use, distribution and reproduction in any medium provided that the original work is properly attributed. and 2-arachidonylglycerol (2-AG) (Ohno-Shosaku and Kano, 2014). Although some evidence implicates AEA in mediating eCB-LTD in dorsal striatum (Ronesi et al., 2004; Ade and Lovinger, 2007) and both presynaptic CB1R- and postsynaptic TRPV1 (transient receptor potential cation channel subfamily $V$ member 1 )-dependent LTD in the NAc (Grueter et al., 2010), we focused on 2-AG because its contribution to eCB-LTD in the NAc is linked to the regulation of motivated behavior (Novak et al., 2010; Bilbao et al., 2020; Folkes et al., 2020). Formation of 2-AG at excitatory synapses in the NAc is mediated by the 2-AG signalosome-a postsynaptic multiprotein complex composed of mGlu5, enzymes involved in 2-AG production, and Homer scaffolding proteins (Piomelli, 2014). Stimulation of mGlu5 activates phospholipase-C, which cleaves plasma membrane PIP2 (phosphatidylinositol 4,5-bisphosphate) to form 1,2-diacylglycerol (DAG), a second messenger that is hydrolyzed by DAG lipase- $\alpha$ (DGL) to yield 2-AG, which acts on presynaptic CB1Rs (Jung et al., 2007).

NAc synaptic depression, evoked electrically or via pharmacological activation of mGlu5, is abolished $1 \mathrm{~d}$ after acute noncontingent cocaine (Fourgeaud et al., 2004; Grueter et al., 2010), 14 d after repeated noncontingent cocaine injections (Huang et al., 2011), and after $>35 \mathrm{~d}$ of withdrawal from extended-access cocaine selfadministration (McCutcheon et al., 2011; Scheyer et al., 2014). Neither acute cocaine administration (Fourgeaud et al., 2004) nor incubation of craving (McCutcheon et al., 2011) impairs CB1R function, implying a postsynaptic locus. Indeed, alterations in the 2-AG signalosome have been observed after regimens leading to the loss of this synaptic depression, namely a reduction in mGlu5 surface expression (Fourgeaud et al., 2004; Huang et al., 2011; Loweth et al., 2014) and altered Homer levels (Fourgeaud et al., 2004) or Homer-mGlu5 associations (Loweth et al., 2014). However, no studies have assessed the enzymatic activity of DGL or its associations within the 2-AG signalosome after cocaine exposure.

Here, we used coimmunoprecipitation (co-IP) to assess associations between DGL and other components of the signalosome and also assayed enzymatic activity of DGL in the NAc core. Compared with saline controls, associations between total and phosphorylated $\mathrm{Ca}^{2+} /$ calmodulin-dependent protein kinase II (CaMKII) and DGL were increased at incubation-relevant withdrawal times. This was accompanied by decreased DGL activity, as predicted by studies demonstrating that CaMKII phosphorylation reduces DGL activity (Shonesy et al., 2013; Park et al., 2017). However, our results fall short of demonstrating that loss of this synaptic depression contributes to incubated craving. In fact, other findings argue that this synaptic depression promotes reward seeking (Novak et al., 2010; Bilbao et al., 2020; Mitra et al., 2021).

\section{Materials and Methods}

\section{Subjects and surgery}

All animal procedures were performed in accordance with the regulations of the animal care committees of 
Rosalind Franklin University and the Oregon Health \& Science University, and with the National Institutes of Health (NIH) Guide for the Care and Use of Laboratory Animals. Male Sprague Dawley rats (Envigo) weighing 275$300 \mathrm{~g}$ were housed three to a cage under a reverse $12 \mathrm{~h}$ light/dark cycle with food and water available ad libitum. One week after arrival, rats were implanted with a jugular catheter under ketamine/xylazine anesthesia $(80 / 10 \mathrm{mg} / \mathrm{kg}$, i.p.). Before surgery, rats received an injection of the analgesic Banamine (flunixin meglumine, $2.5 \mathrm{mg} / \mathrm{kg}$, s.c.) to minimize postoperative discomfort. Thereafter, rats were single housed for $7 \mathrm{~d}$ before beginning self-administration training. Catheters were flushed daily with cefazolin $(100 \mathrm{mg} / \mathrm{ml}$ in sterile $0.9 \%$ saline; $0.15 \mathrm{ml}$ ) during this period to prevent infection and maintain catheter patency.

\section{Drug self-administration and cue-induced seeking tests}

Cocaine was obtained from the National Institute on Drug Abuse and dissolved in $0.9 \%$ saline. Rats self-administered cocaine $(0.5 \mathrm{mg} / \mathrm{kg} /$ infusion in a $100 \mu \mathrm{l} / \mathrm{kg}$ volume over $3 \mathrm{~s}$ ) or saline, during 10 consecutive sessions (6 $\mathrm{h} / \mathrm{d}$ starting at zeitgeber time 15), in a chamber equipped with two nose-poke holes. Active hole nose pokes resulted in intravenous delivery of the drug paired with a 20 $s$ light cue (white light illuminating the active hole) on a fixed ratio 1 schedule. Each infusion was followed by a 20 $\mathrm{s}$ time-out period. Nose poking in the inactive hole had no consequences. After $10 \mathrm{~d}$ of training, rats underwent forced abstinence in home cages and were handled weekly until being used for experiments on or after WD40. This regimen reliably results in incubation of cocaine craving that is robustly expressed during this withdrawal period (Conrad et al., 2008; Loweth et al., 2014). Therefore, we did not assess incubation of craving in rats used in some of our biochemical studies. However, two cohorts of rats, used for DGL activity assays, underwent cue-induced seeking tests after the same cocaine self-administration regimen to verify incubation of craving. During these seeking tests, responses in the previously active hole delivered the light cue but no drug. Responding under these conditions is our operational measure of cue-induced cocaine craving. One cohort underwent seeking tests on WD1 and WD40, and the other on WD1 and WD42.

\section{Coimmunoprecipitation}

Rats were decapitated and bilateral NAc core was rapidly dissected from two $1 \mathrm{~mm}$ slices prepared with a brain matrix (ASI Instruments) using a $1.5 \mathrm{~mm}$ biopsy punch (Thermo Fisher Scientific). NAc punches were homogenized in $500 \mu$ l of lysis buffer consisting of 25 mM HEPES, $\mathrm{pH}$ 7.4, $500 \mathrm{~mm} \mathrm{NaCl}, 2 \mathrm{~mm}$ EDTA, $20 \mathrm{~mm} \mathrm{NaF}, 1 \mathrm{~mm}$ PMSF, $0.1 \%$ NP-40 (v/v), 1 mm NaOV, $1 \times$ protease inhibitor cocktail Set 1 (Millipore), 1\% Triton, and 0.5\% deoxycholate. Three micrograms of DGL- $\alpha$ antibody (a gift from Dr. Ken Mackie, Indiana University, Bloomington), validated in previous studies (Katona et al., 2006; Keimpema et al., 2010), was incubated overnight at $4^{\circ} \mathrm{C}$ with protein A/G agarose slurry. The pellet containing antibody-coated beads was then incubated overnight at $4^{\circ} \mathrm{C}$ with $100 \mu \mathrm{g}$ of NAc core tissue homogenate. The agarose-bound antibody was pelleted by centrifugation to isolate the bound fraction (two rounds of immunoprecipitation were performed to maximize recovery). The combined bound fraction was suspended in $2 \times$ Laemmli sample buffer with $1 \times$ XT Reducing Agent (Bio-Rad) in a volume equal to the input tissue volume. Samples were heated to $100^{\circ} \mathrm{C}$ for $3 \mathrm{~min}$ and stored at $-20^{\circ} \mathrm{C}$. Samples were run on $4-12 \%$ Bis-Tris gels (BIO-RAD) and transferred to PVDF membranes for immunoblotting. Membranes were then washed in distilled $\mathrm{H}_{2} \mathrm{O}\left(\mathrm{dH}_{2} \mathrm{O}\right)$ and blocked with $1 \%$ normal goat serum with $5 \%$ nonfat dry milk in $0.05 \%$ Tween-20 in TBS, $\mathrm{pH} 7.4$, for $1 \mathrm{~h}$ at room temperature. Membranes were incubated overnight at $4{ }^{\circ} \mathrm{C}$ with antibodies to mGlu5 (1:10,000; catalog \#AB5675, Millipore Sigma), CaMKII (1:1000; catalog \#3362, Cell Signaling Technology), pThr286 CaMKII (1:1000; catalog \#p1005-286, Phospho Solutions), p-Ser (1:120; catalog \#sc-81514, Santa Cruz Biotechnology), Homer1b/c (1:200; catalog \#sc55 463, Santa Cruz Biotechnology), or Homer2 (1:500; catalog \#H00009455-B01P, Abnova). The mGlu5 dimer band ( $\sim 260 \mathrm{kDa})$ was analyzed because it represents the functional pool of these receptors (Jingami et al., 2003). GAPDH was used as a loading control when immunoblotting total tissue homogenates. Secondary antibodies to rabbit or mouse lgG light chain were used (catalog \#211-032-171 or \#115-035174, Jackson ImmunoResearch) in co-IP studies to prevent interference with the Homer band ( $\sim 5 \mathrm{kDa}$ ) by the heavy chain ( $\sim 50 \mathrm{kDa})$. Visualization was achieved by chemiluminescence (GE Healthcare). Immunoblots were analyzed with TotalLab (Life Sciences Analysis Essentials). Data were excluded only if imperfections in the gel or blot interfered with analysis. Across all blots, data points for two samples were removed from analysis. These consisted of one cocaine and one saline data point from the synaptoneurosome preparation.

\section{Synaptoneurosome preparation}

Rats were decapitated and bilateral NAc tissue (primarily core) was rapidly dissected from a $2 \mathrm{~mm}$ coronal slice prepared with a brain matrix (ASI Instruments). Immediately following dissection, synaptoneurosomes were prepared according to published protocols (Most et al., 2015; Workman et al., 2015; Werner et al., 2018). NAc punches were homogenized in $500 \mu$ l of homogenization buffer [HB; 20 mM HEPES, 0.5 mm EGTA, 1× Proteasome Inhibitor Cocktail Set 1 (Millipore)]. Homogenates were passed through a 100- $\mu \mathrm{m}$-pore filter and then through a 5- $\mu \mathrm{m}$-pore filter (Millipore; both filters were prewashed with HB). After homogenates were passed through each filter, filters were washed with $50 \mu \mathrm{l}$ of $\mathrm{HB}$, and the washes were added to homogenates to maximize yield. Homogenates were then centrifuged at $14,000 \times g$ for $20 \mathrm{~min}$ at $4^{\circ} \mathrm{C}$. The pellet, which contains the synaptoneurosomes, was frozen on dry ice, stored at $-80^{\circ} \mathrm{C}$, and ultimately lysed in lysis buffer $[0.605 \times g$ Tris- $\mathrm{HCl}, 0.25 \times g$ sodium deoxycholate, $0.876 \times g \mathrm{NaCl}$, $1 \mu \mathrm{g} / \mathrm{ml}$ PMSF, $5 \mathrm{ml}$ of $20 \%$ SDS, and $1 \times$ Protease Inhibitor Cocktail Set 1 (Millipore) in $100 \mathrm{ml}$ of $\mathrm{dH}_{2} \mathrm{O}$ ] for immunoblotting. NAc synaptoneurosomes prepared from individual rats 
(10 $\mu \mathrm{g}$ protein/lane) were mixed 1:1 with $2 \times$ sample treatment buffer (catalog \#161-0737, BIO-RAD) and analyzed by SDSPAGE and immunoblotting. $\beta$-Tubulin was used as a loading control.

\section{DGL activity}

Rats were decapitated, and bilateral NAc was rapidly dissected as described above for synaptoneurosome preparation. Lipase activity was subsequently assayed using fluorescence resonance energy transfer (FRET) as adapted from a previous report (Johnston et al., 2012). Briefly, $600 \mu$ of homogenization buffer [50 mм HEPES, $\mathrm{pH}$ 7.0, $250 \mathrm{~mm}$ sucrose, $1 \mathrm{~mm}$ Roche PhosStop (Millipore Sigma), $0.5 \mathrm{~mm}$ tris (2-carboxyethyl)phosphine (TCEP), $0.01 \mathrm{~mm}$ leupeptin, $0.001 \mathrm{~mm}$ pepsin] was added to punched NAc tissue and macerated by a 27 gauge needle. The solution was homogenized with an electric pestle and then centrifuged for $30 \mathrm{~min}$. Supernatant was removed from the pellet and discarded. The pellet was resuspended in $300 \mu$ l of membrane resuspension buffer (same as homogenization buffer but without sucrose), then vortexed and briefly sonicated on ice. Using a Bradford assay, protein concentration of the punched NAc tissue was determined. A 96-well plate was then prepared on ice with protein samples in triplicate at $40 \mu \mathrm{g}$ total protein/well. As a negative control, tissue from cerebellum was run in the absence and presence of the DAGL inhibitor DO34 (2 $\mu \mathrm{M})$. The FRET reporter compound MRJ20 (compound \#17 in Johnston et al., 2012), a FRETbased substrate for DGL, was made in-house (Vanderbilt Chemical Synthesis Core, Nashville, TN). MRJ20 was added to the assay buffer (50 mm HEPES, pH 7.0, $0.5 \mathrm{~mm}$ TCEP, $1 \mathrm{~mm}$ PhosStop) to reach a final concentration of 2 $\mu \mathrm{M}$. The assay buffer was then vortexed and sonicated on ice for $2 \mathrm{~min}$. The plate was then taken to a prewarmed fluorescent plate reader (Synergy H4, BioTek), and the recently sonicated assay buffer was pipetted into the wells at $150 \mu \mathrm{l}$. The reader maintained a constant $37^{\circ} \mathrm{C}$ temperature and took fluorescent measurements every minute for $30 \mathrm{~min}$. Samples were then analyzed for relative fluorescent units (RFU) over the $30 \mathrm{~min}$, and a line of best fit for RFU per minute determined relative slopes ( $\triangle \mathrm{RFU} / \mathrm{mi}-$ nute) for each sample (GraphPad Prism).

\section{Statistical analyses}

Data are expressed as the mean \pm SEM. Groups were compared with unpaired (between group) or paired (within group) $t$ tests. Pearson correlation coefficients were used to assess the linear correlation between the magnitude of incubation of craving and DGL activity. Differences between experimental groups were considered statistically significant when $p<0.05$.

\section{Results}

\section{Incubation of cocaine craving is not associated with changes in DGL expression or its association with mGlu5 receptors and Homer scaffolding proteins}

Three cohorts of rats underwent extended-access saline or cocaine self-administration $(10$ sessions of $6 \mathrm{~h} / \mathrm{d}$; the three cohorts are depicted in Fig. $1 A$ top, Fig. $1 A$ bottom, and Fig. 2A). In all cases, biochemical analyses of NAc were conducted on or after WD40, when incubation of cocaine craving has plateaued (Lu et al., 2004) and stable CP-AMPAR elevation (Wolf and Tseng, 2012) and loss of mGlu5-dependent synaptic depression (McCutcheon et al., 2011; Scheyer et al., 2018) have been observed. The core subregion was analyzed, because of its critical role in the incubation of cocaine craving (Conrad et al., 2008; Guillem et al., 2014; Loweth et al., 2014). In NAc homogenates prepared from the first cohort of rats (Fig. 1A, top), we found that DGL levels did not differ between cocaine and saline groups (Fig. 1B, top). NAc tissue from the second cohort (Fig. 1A, bottom) was used to prepare synaptoneurosomes, a subcellular fraction enriched for the postsynaptic density (Hollingsworth et al., 1985; Quinlan et al., 1999; Most et al., 2015; Workman et al., 2015), on WD40. DGL levels in NAc synaptoneurosomes likewise did not differ between cocaine and saline groups (Fig. 1B, bottom).

NAc tissue from the third cohort was used to assess the DGL associations with Homer2 and mGlu5 by immunoprecipitating DGL and measuring bound Homer and mGlu5 levels (Fig. 2). mGlu5 and its association with Homer scaffolding proteins are necessary for 2-AG signaling at excitatory synapses (Roloff et al., 2010) and DGL associations with Homer scaffolding proteins are required for membrane-bound DGL activity (Jung et al., 2007). Although DGL does not directly bind to mGlu5, we detected bound mGlu5 in DGL immune complexes (Fig. 2B, Extended Data Fig. 2-1A) and also detected bound DGL in mGlu5 immune complexes (Extended Data Fig. 2$1 \mathrm{~A})$, presumably via intermediate Homer interactions. Homer1b/c was not detected in our DGL immune complexes in NAc core (Extended Data Fig. 2-1B,C). We therefore focused on Homer2, which has been implicated in the actions of cocaine in the NAc (Szumlinski et al., 2008). DGL associations with Homer2 and mGlu5 were unaffected by cocaine self-administration and prolonged withdrawal (Fig. 2B). These results suggest that impairments in physical association between these components of the 2-AG signalosome are not responsible for impaired mGlu5-dependent synaptic depression after incubation of cocaine craving.

\section{Incubation of cocaine craving is associated with increased interactions between CaMKII and DGL}

The loss of mGlu5-dependent synaptic depression after incubation of cocaine craving may be attributable to interactions that modulate DGL activity. For instance, CaMKII $\alpha$ and CaMKII $\beta$ bind DGL, and studies in dorsal striatum have found that CaMKII phosphorylation of DGL inhibits its activity and, conversely, that 2-AG-dependent depolarization-induced suppression of excitation is augmented by pharmacological inhibition of CaMKII (Shonesy et al., 2013). Furthermore, increased CaMKII activity is implicated in stress-induced impairment of endocannabinoid-mediated synaptic depression in the lateral habenula (Park et al., 2017). To determine whether interactions between DGL and CaMKII are affected during late withdrawal from cocaine self-administration, different 
A

Self-administration training

WD $>40$ Total $D G L(N=9 \operatorname{coc} / 7$ sal $)$
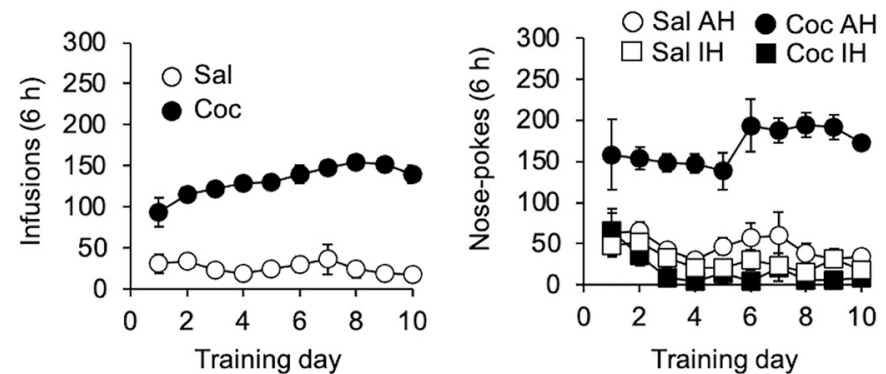

WD40 synaptoneurosomes $(\mathrm{N}=8 \mathrm{coc} / 8 \mathrm{sal})$

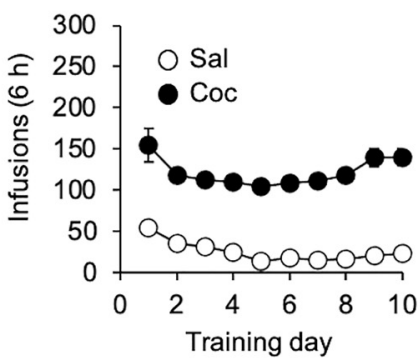

B

DGL levels
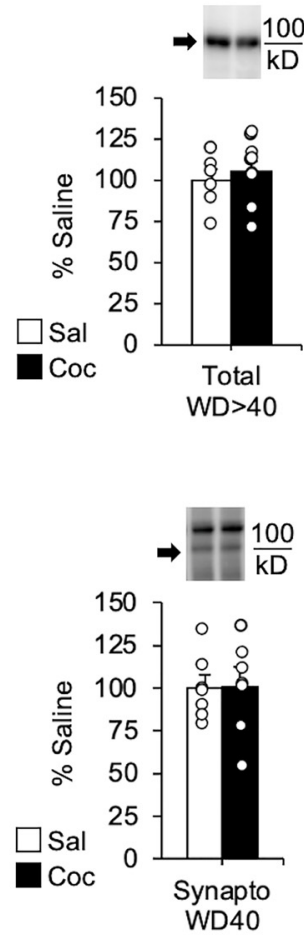

Figure 1. DGL protein levels in the NAc core are unchanged after prolonged withdrawal from extended-access cocaine (Coc) selfadministration. $\boldsymbol{A}$, Two cohorts of rats underwent extended-access self-administration of cocaine or saline (6 h/d for $10 \mathrm{~d})$, destined for preparation of NAc core homogenates after WD40 (WD > 40; top) or NAc synaptoneurosomes on WD40 (bottom). Shown are the number of infusions (left graphs) or number of active hole $(\mathrm{AH})$ and inactive hole $(\mathrm{IH})$ nose pokes (right graphs) on the $10 \mathrm{~d}$ of self-administration training. $N$ values are given in the figure. $\boldsymbol{B}$, DGL protein levels do not differ between saline and cocaine groups based on immunoblot analysis of NAc homogenates (top) or synaptoneurosomes (bottom). Data are expressed as the percentage of controls ( $n=7-9$ rats/group; mean \pm SEM). Representative lanes from immunoblots (cropped) are shown for a saline rat (left) and a cocaine rat (right). Arrows indicate bands analyzed, and lines indicate the location of the molecular weight marker. Saline and cocaine groups were compared with unpaired $t$ tests (n.s.).

A

Self-administration training

WD55 DGL IPs $(\mathrm{N}=10 \mathrm{coc} / 10 \mathrm{sal})$

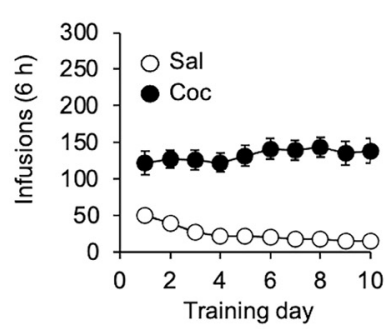

B DGL IP

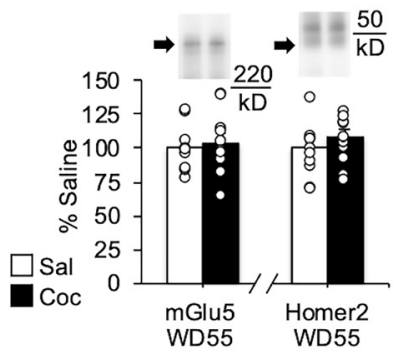

Figure 2. Associations between components of the 2-AG signalosome in the NAc core are unchanged after prolonged withdrawal from extended-access cocaine (Coc) self-administration. $\boldsymbol{A}$, Rats underwent extended-access self-administration of cocaine or saline $(6 \mathrm{~h} / \mathrm{d}$ for $10 \mathrm{~d})$, destined for the preparation of NAc core homogenates on WD55. Shown are the number of infusions (left graph) or the number of active hole $(\mathrm{AH})$ and inactive hole $(\mathrm{IH})$ nose pokes (right graph) during the $10 \mathrm{~d}$ of self-administration training. $N$ values are given in the figure. $\boldsymbol{B}$, Coimmunoprecipitation experiments assessing the physical associations between DGL and $\mathrm{mGlu} 5$ or Homer2 in NAc tissue obtained on WD55 (also see Extended Data Figure 2-1). DGL was immunoprecipitated from NAc core homogenates, and the bound fraction was immunoblotted for mGlu5 or Homer2. Data are expressed as the percentage of saline (Sal) controls $(n=9-10$ rats/group; mean \pm SEM). Representative lanes from immunoblots (cropped) are shown for a saline rat (left) and a cocaine rat (right). Arrows indicate bands analyzed, and lines indicate the location of the molecular weight marker. IB, Immunoblot; IP, Immunoprecipitation. Saline and cocaine groups were compared with unpaired $t$ tests (n.s.). 
DGL IP, CaMKII IB (WD55)

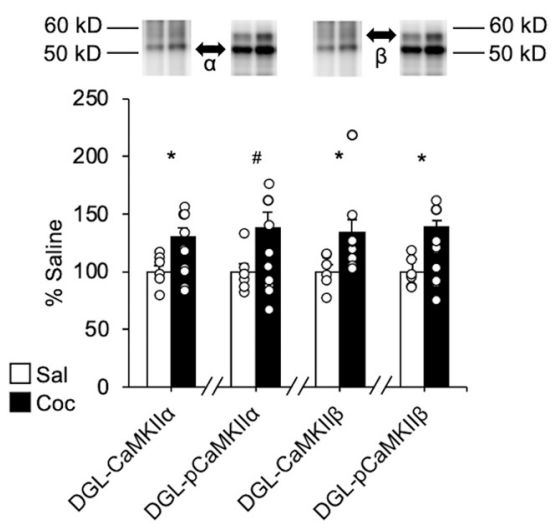

Figure 3. The association of CaMKII with DGL is increased in the NAc core after prolonged withdrawal from extended-access cocaine (Coc) self-administration. Coimmunoprecipitation experiments assessed the physical associations between DGL and phosphorylated or total CaMKII $\alpha$ and CaMKII $\beta$ in NAc core homogenates prepared on WD55 (same rats for which behavioral data are shown in Fig. 2). Also see Extended Data Fig. 3-1. Data are expressed as the percentage of the saline (Sal) control group ( $n=6-10$ rats/group; mean $\pm \mathrm{SEM}$; unpaired $t$ tests, ${ }^{*} p<0.05$, $\# p=0.0501$ vs saline). Representative lanes from immunoblots (cropped) are shown for a saline rat (left) and a cocaine rat (right). Arrows indicate bands analyzed, and lines indicate the location of the molecular weight marker. IB, Immunoblot.

aliquots of the same tissue samples used for the experiment depicted in Figure 2 were used to immunoprecipitate DGL and measure bound CaMKII by immunoblotting. DGL associations with total CaMKII $\alpha\left(t_{(14)}=2.59\right.$, $p=0.021)$, total CaMKII $\beta\left(t_{(14)}=2.30, p=0.037\right)$, phosphorylated (Thr286) CaMKII $\alpha\left(t_{(14)}=2.14, p=0.050\right)$, and phosphorylated CaMKII $\beta\left(t_{(14)}=2.59, p=0.014\right)$ were all increased in the cocaine group relative to saline controls (Fig. 3). CaMKII phosphorylates DGL on two serine residues (Shonesy et al., 2013). Therefore, to determine whether CaMKII associations with DGL also led to detectable increases in DGL phosphorylation, other aliquots of these DGL immunoprecipitated samples were subjected to SDS-PAGE followed by immunoblotting with an antibody that recognizes phosphorylated serine residues. $A$ band was detected at the molecular weight of DGL $(\sim 100 \mathrm{kDa})$, but its intensity did not differ between saline and cocaine groups (Extended Data Fig. 3-1). However, these data are not conclusive. Whereas the lysis buffer for initial homogenization of tissue contained a reagent for inhibiting phosphatases $(20$ $\mathrm{mm} \mathrm{NaF}$ ), our washing buffer for processing the bound fraction during the immunoprecipitation protocol did not, because at the time the tissue was processed, we did not intend to use it to detect protein phosphorylation. Therefore, DGL might have been dephosphorylated during the lengthy immunoprecipitation protocol (see Materials and Methods).

\section{DGL activity is reduced in the NAc core after incubation of cocaine craving}

Based on earlier studies (Shonesy et al., 2013; Park et al., 2017), the observation of increased CaMKII association with DGL suggests that DGL activity will be reduced after prolonged withdrawal from extended-access cocaine self-administration. To test this, a new cohort of rats was generated (nine saline and nine cocaine; Fig. 4A). Cue-induced seeking tests were conducted on WD1 and WD40 to confirm incubation of craving $\left(t_{(16)}=\right.$ 3.748, $p=0.002$; Fig. 4B). On WD45, NAc tissue (primarily core) was harvested and snap frozen. DGL activity was subsequently assayed using FRET (Johnston et al., 2012). Compared with saline controls, the cocaine group was found to have reduced DGL activity $\left(t_{(14)}=2.54, p=0.024\right.$; Fig. $4 C$ ). Furthermore, in this initial cohort there was a trend for an inverse relationship between DGL activity in late withdrawal (WD40) and the magnitude of incubation of craving for rats in the cocaine group, expressed as the ratio of active hole nose pokes during $30 \mathrm{~min}$ seeking tests conducted on WD40 versus WD1 for each rat $(p=0.08$; Fig. 4D).

We attempted to replicate this using an additional cohort of late withdrawal cocaine rats (Fig. $5 A$ ) for which incubation of craving was demonstrated (Fig. $5 B$ ). In this second cohort, we observed no significant relationship between DGL activity and the magnitude of incubation (Fig. 5D). We also assessed this relationship after combining the two cohorts. The second cohort was run over a year after the first, and required re-establishment of the assay. Perhaps for this reason, absolute RFU/minute values for the two cohorts differed substantially (compare Fig. $4 C$ with $5 C$ and Extended Data Fig. 5-1). Because the second cohort did not contain saline controls (they were not run because our focus was on understanding the correlation between DGL activity and incubation in the cocaine group), we could not combine the two cohorts by normalizing to saline control values. As an alternative approach, mean values ( $\triangle \mathrm{RFU} /$ minute) were calculated for each cohort, and individual rat values were expressed as a percentage of the cohort mean. We found no significant difference between DGL activity and incubation when the cohorts were combined in this manner (Fig. 5E). Overall, these results show that DGL activity is reduced in the NAc core after prolonged withdrawal from extended-access cocaine self-administration, and that the level of DGL activity in late withdrawal cocaine rats does not correlate with the magnitude of incubation.

\section{Discussion}

Enduring vulnerability to relapse is encoded by synaptic plasticity in the NAc (Lüscher, 2016; Scofield et al., 2016; Wolf, 2016). An important form of synaptic depression in the NAc is elicited by postsynaptic mGlu5 stimulation, resulting in the generation of eCBs, which travel in a retrograde fashion to stimulate presynaptic CB1 receptors and reduce glutamate release (see Introduction). After the incubation of cocaine craving, this mGlu5/CB1R-dependent synaptic depression is lost in the NAc core (McCutcheon et al., 2011; Scheyer et al., 2014, 2018). This is accompanied by reduced surface mGlu5 and reduced mGlu5-Homer interactions (Loweth et al., 2014). Coupled with intact synaptic depression in the NAc of cocaine-incubated animals in response to direct CB1R activation (McCutcheon et al., 2011), 
A

Self-administration training

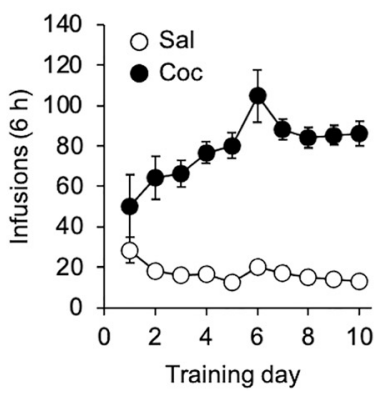

C

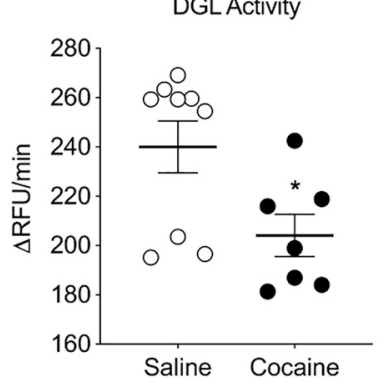

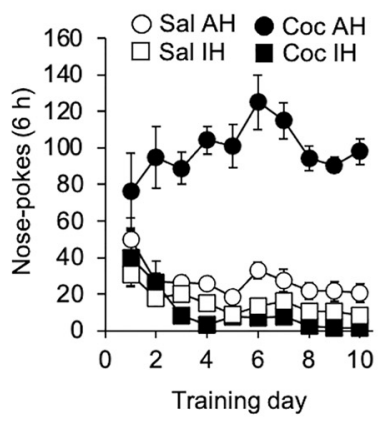

D Incubation and DGL activity

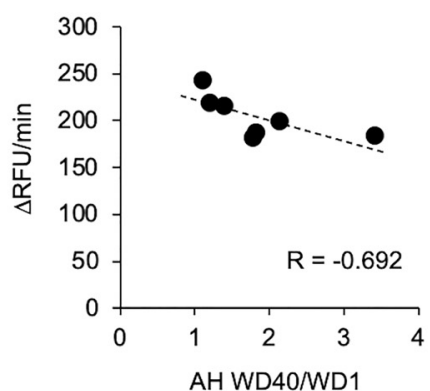

B

Incubation of craving

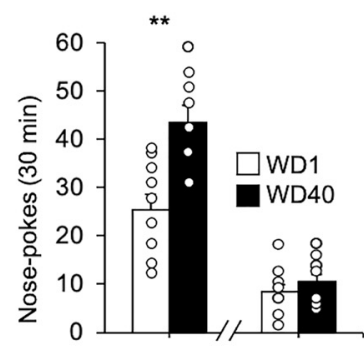

Figure 4. Reduction of DGL activity in the NAc after prolonged withdrawal from extended-access cocaine (Coc) self-administration. $\boldsymbol{A}$, Training. Rats self-administered saline or cocaine for $6 \mathrm{~h} / \mathrm{d}$ for $10 \mathrm{~d}$ ( $n=9 \mathrm{rats} / g$ roup). Shown are the number of infusions (left graph) or number of active hole $(\mathrm{AH})$ and inactive hole $(\mathrm{IH})$ nose pokes (right graph). $\boldsymbol{B}$, Seeking tests on WD1 and WD40. During the 30 min test, $\mathrm{AH}$ nose pokes led to contingent presentation of the $20 \mathrm{~s}$ light cue previously paired with cocaine infusion, but no cocaine. Shown are $\mathrm{AH}$ and $\mathrm{IH}$ nose pokes during the seeking test (mean $\pm \mathrm{SEM}$; paired $t$ test, ${ }^{* *} p<0.01$ vs WD1). $\boldsymbol{C}, \mathrm{DGL}$ activity. Five days after the WD40 seeking test, bilateral NAc punches comprised primarily of NAc core were snap frozen. Fluorescence resonance energy transfer assay of DGL activity was then conducted and results expressed as $\Delta R F U /$ minute. The cocaine group shows reduced DGL activity ( $n=7-9$ rats/group; mean \pm SEM; unpaired $t$ test, ${ }^{*} p<0.05$ vs saline). $\boldsymbol{D}$, Linear regression evaluating the relationship between DGL activity in NAc core of cocaine animals versus the magnitude of incubation of craving expressed as WD40/WD1 AH nose pokes ( $n=7$ rats; $R=-0.692, p=0.085)$.

these results suggest a postsynaptic locus for the loss of mGlu5/CB1R-dependent synaptic depression.

Here, we assessed the postsynaptic mGlu5 signaling complex that mediates the generation of 2-AG (the 2-AG signalosome; Piomelli, 2014) in the NAc core subregion. No changes were found in DGL protein levels or its physical association with mGlu5 and Homer proteins (Figs. 1, 2 ), indicating that the loss of mGlu5/CB1R-dependent synaptic depression does not reflect reductions in physical associations between these components of the 2AGsignalasome. However, we observed increased associations between DGL and CaMKII (Fig. 3), an interaction previously demonstrated to result in DGL phosphorylation and reduced DGL activity (Shonesy et al., 2013). For these biochemical studies (Figs. 1-3), we did not demonstrate incubation of craving in the rats used, but we made measurements at withdrawal times $(W D \geq 40)$ when incubation is reliably demonstrated after the same regimen (Conrad et al., 2008; Loweth et al., 2014; Figs. 4, 5). Next, we measured the enzymatic activity of DGL, the enzyme that catalyzes 2-AG production (Piomelli, 2014). As might be expected from our observation of increased DGLCaMKII association and previous results mentioned above (Shonesy et al., 2013), we observed a decrease in DGL activity in NAc core tissue obtained from rats demonstrated to have undergone incubation of cocaine craving compared with saline controls (Fig. 4). Although we lack evidence for a causal relationship between the increased DGL-CaMKII association and the observed reduction in DGL activity, it is tempting to speculate that the increased DGL-CaMKII association may contribute to the loss of mGlu5/CB1R-dependent synaptic depression after prolonged cocaine withdrawal. Finally, we found that DGL activity in late withdrawal (WD40 or WD42) was not significantly correlated with the magnitude of incubation (expressed as the ratio of active hole nose pokes during seeking tests conducted on WD40 or WD42 vs WD1) for individual cocaine rats (Figs. 4, 5).

We note that there are several limitations to our study. First, we did not include cocaine WD1 rats or yoked cocaine controls in our biochemical studies. These groups would be necessary to establish that observed changes are specific to incubation and not merely the result of cocaine self-administration or cocaine exposure, respectively. A second limitation of our study is that the use of homogenates or synaptoneurosomes precludes the 
A

Self-administration training

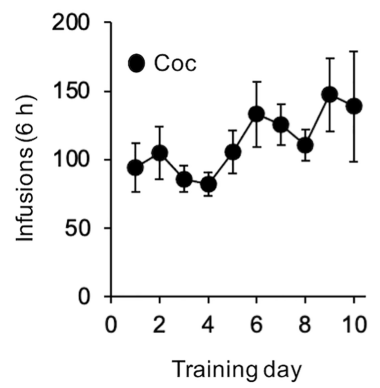

C

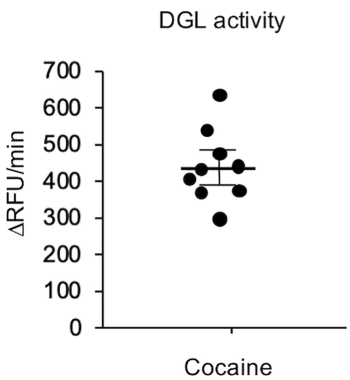

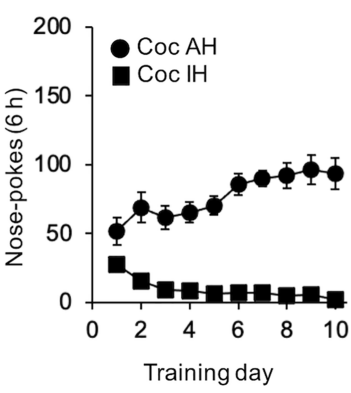

D

D Incubation and DGL activity

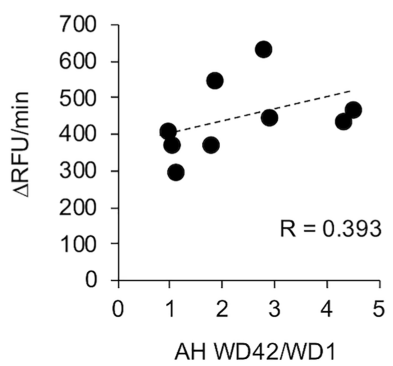

B Incubation of craving

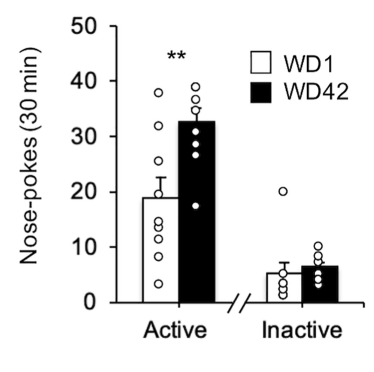

E Incubation and DGL activity

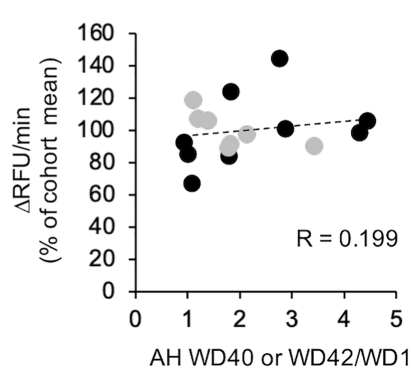

Figure 5. DGL activity in the NAc after prolonged withdrawal from extended-access cocaine (Coc) self-administration does not correlate with the magnitude of incubation of craving. $\boldsymbol{A}$, Training. Rats self-administered cocaine for $6 \mathrm{~h} / \mathrm{d}$ for $10 \mathrm{~d}$ ( $n=9 \mathrm{rats})$. Shown are the number of infusions (left graph), and the number of active hole (AH) and inactive hole (IH) nose pokes (right graph). $\boldsymbol{B}$, Seeking tests on WD1 and WD42. Shown are AH and IH nose pokes during the 30 min seeking test (mean \pm SEM; paired $t$ test, ${ }^{* *} p<0.01$ vs WD1). C, Five days after the WD42 seeking test, bilateral NAc punches comprised primarily of NAc core were snap frozen and DGL activity was determined using fluorescent resonance energy transfer (Extended Data Fig. 5-1). D, Linear regression evaluating DGL activity versus the magnitude of incubation of craving expressed as WD42/WD1 AH nose pokes. No significant correlation between DGL activity and incubation was found ( $n=9$ rats; $R=0.393$; n.s.). $E$, Combined linear regression evaluating $D G L$ activity versus the magnitude of incubation of craving from both cocaine cohorts (shown in Fig. $4 A$ and Fig. $5 A$ ). From comparison of Fig. $4 C$ and Fig. $5 C$, it is apparent that absolute RFU per minute values for the two cohorts differed substantially (the cohorts were run over a year apart). To enable the data from the cohorts to be combined, mean values ( $\Delta$ RFU/minute) were calculated for each cohort and individual rat values ( $\triangle \mathrm{RFU} /$ minute) were expressed as percentage of the cohort mean (Fig. $5 \mathrm{~A}$ cohort in black, $n=7$; Fig. $4 A$ cohort in gray, $n=9 ; R=0.199$, n.s.). RFU, Relative Fluorescence Units.

detection of potentially cell type-specific $\left(D_{1}\right.$ vs $\left.D_{2} M S N s\right)$ or input-specific adaptations in DGL activity. This could be one reason why we failed to identify a clear role for DGL adaptations in the incubation of craving. For example, one prominent incubation-related adaptation, synaptic insertion of CP-AMPARs, can occur on both $D_{1}$ and $D_{2}$ MSNs (Terrier et al., 2016; Wolf, 2016) but demonstrates input specificity (Lee et al., 2013; Ma et al., 2014; Pascoli et al., 2014; Terrier et al., 2016). A third limitation is that saline controls were not included in the experiment shown in Figure 5, as discussed extensively in Results. Finally, male rats were used for this study, in accordance with the NIH grant supporting this project. Given recent work showing sex differences in the incubation of cocaine craving (Kerstetter et al., 2008; Nicolas et al., 2019), future studies should explore similar questions in female rats.

\section{Role for CaMKII in loss of mGlu5/CB1R-dependent synaptic depression after incubation of cocaine craving}

CaMKII is a $\mathrm{Ca}^{2+}$-activated enzyme that is best known for its critical role in early and late phases of long-term potentiation (LTP) but also participates in many other mechanisms regulating synaptic function (Lisman et al., 2002, 2012; Hell, 2014; Bayer and Schulman, 2019). There are four isoforms derived from four genes $(\alpha, \beta, \gamma$, and $\delta$ ), with the CaMKII $\alpha$ and $\mathrm{CaMKII} \beta$ isoforms mainly expressed in the brain. The regulatory site of each isoform contains a phosphorylation site (Thr286 for CaMKII $\alpha$ and Thr287 for CaMKII $\beta$ ) that can generate autonomous kinase activity (see reviews cited above).

We explored a role for CaMKII in the loss of mGlu5/ CB1R-dependent synaptic depression after incubation of craving based on studies in dorsal striatum showing that CaMKII $\alpha$ and CaMKII $\beta$ bind DGL, CaMKII phosphorylation of DGL inhibits its activity, and, conversely, that 2AG-dependent depolarization-induced suppression of excitation is augmented by pharmacological inhibition of CaMKII (Shonesy et al., 2013). Furthermore, increased CaMKII activity is implicated in stress-induced impairment of endocannabinoid-mediated synaptic depression in the lateral habenula (Park et al., 2017). Consistent with these prior findings, we found increased associations between DGL and both total and phosphorylated CaMKII $\alpha$ 
and CaMKII $\beta$ in NAc core tissue from cocaine rats (examined at an incubation-relevant late withdrawal time) versus saline controls. Furthermore, we observed a significant reduction in DGL activity in rats that had undergone incubation of craving compared with saline controls. These results suggest that CaMKII contributes to loss of mGlu5/ CB1R-dependent synaptic depression after incubation. In theory, slice physiology experiments could directly test this relationship by determining whether acute CaMKII inhibition restores mGlu5/CB1R-dependent synaptic depression in NAc core MSNs from rats that have undergone incubation of cocaine craving. A practical concern is that commercially available inhibitors are not effective against the autophosphorylated enzyme, although new inhibitors are under development (Nassal et al., 2020).

Our findings are not the first to implicate CaMKII in neuroadaptations in the NAc after cocaine self-administration. For example, CaMKII $\alpha$, but not $\mathrm{CaMKII} \beta$, mRNA levels increased in NAc shell after cocaine self-administration and in cocaine-yoked controls relative to saline self-administering animals, likely via histone H3 acetylation; the increase correlated with motivation for cocaine measured using a progressive ratio schedule, while knockdown of CaMKIl $\alpha$ in the NAc shell decreased motivation for cocaine (Wang et al., 2010). In another study, cocaine self-administration followed by extinction training did not alter CaMKII phosphorylation in NAc shell or core; however, cocaine-primed reinstatement was associated with an increase in NAc shell CaMKII phosphorylation, and intra-NAc shell CaMKII inhibition via KN-93 attenuated reinstatement (Anderson et al., 2008). During abstinence, increased $\mathrm{CaMKIl} \alpha$ phosphorylation in the NAc was found $24 \mathrm{~h}$ after discontinuing short-access cocaine self-administration relative to yoked saline controls, but this was not observed in a yoked cocaine group, immediately after discontinuing self-administration, or after selfadministration and $7 \mathrm{~d}$ of abstinence (Caffino et al., 2014). In an incubation of cocaine craving study in which rats self-administered saline or cocaine under extended-access conditions, increased ratios of phosphorylated to total CaMKII $\alpha$ and CaMKII $\beta$ were found in NAc postsynaptic density fractions from cocaine rats on WD45 versus cocaine rats on WD1 and saline rats (Ferrario et al., 2011). CaMKII is also implicated in responding to other drugs of abuse. For example, CaMKII activity in NAc shell is required for the enhanced amphetamine intake and sensitized locomotor responding observed in rats previously sensitized to noncontingent amphetamine (Loweth et al., 2008, 2010, 2013).

How might CaMKII become activated during abstinence? While classical studies identified CaMKII activation following acute stimulation in slices (i.e., in conjunction with LTP), CaMKII may also contribute to homeostatic plasticity (Chen et al., 2014; Hell, 2014). Most notably, in cultured hippocampal neurons, prolonged AMPAR blockade $(24 \mathrm{~h})$ increases CaMKII $\beta$ activity, which in turn scales up synaptic levels of homomeric GluA1 receptors; when blockade is discontinued, a presynaptic component of homeostatic adaptation (increased release probability) is revealed in response to $\mathrm{Ca}^{2+}$ entry via CP-AMPARs and the resulting retrograde signaling
(Thiagarajan et al., 2002, 2005; Groth et al., 2011). We have suggested that AMPAR upregulation during cocaine abstinence reflects a homeostatic scaling up of synaptic strength, triggered by relative inactivity during abstinence versus the period of cocaine exposure; while this may normalize synaptic transmission during abstinence, it has the unfortunate consequence of enhancing excitatory responses to drug-related cues when they are presented after abstinence (Boudreau and Wolf, 2005; Conrad et al., 2008; Sun and Wolf, 2009). Likewise, the observation that sustained food restriction upregulates reward responding through the upregulation of NAC CP-AMPARs has been hypothesized to represent a homeostatic response (Carr, 2020). The finding of increased CaMKII phosphorylation in NAc postsynaptic density fractions prepared after incubation of cocaine craving (Ferrario et al., 2011) combined with increased phosphorylation of the DGL-bound CaMKII pool in the present study suggests that CaMKII may play a role after cocaine withdrawal that to some extent parallels that observed after AMPAR blockade in hippocampal neurons (above). The reduction in DGL activity that is observed in parallel with CaMKII activation could be "collateral damage" or it could contribute to the homeostatic response by removing a braking effect on excitatory synaptic transmission. It is also possible that CaMKII activation after incubation of craving is functionally relevant to DGL regulation, but that different homeostatic cascades are involved in CP-AMPAR upregulation (Wang et al., 2018; Loweth et al., 2019).

\section{Relationship between mGlu5/CB1R-dependent synaptic depression and cocaine seeking}

As DGL activity was reduced in rats that underwent incubation of cocaine craving compared with saline controls (above), we tested for a correlation between DGL activity and the magnitude of incubation of craving (expressed relative to baseline craving on withdrawal day 1) for individual cocaine rats in two separate cohorts. Because the expression of incubation requires excitatory synaptic transmission onto NAc core MSN (Wolf, 2016), and DGL activity leading to 2-AG formation leads to reduced glutamate transmission (i.e., synaptic depression), we hypothesized that cocaine rats with the lowest DGL activity might show the strongest incubation of craving. However, we failed to observe a significant correlation between DGL activity and cocaine seeking. This does not rule out a contribution of reduced DGL activity to incubation. It is possible that reduction of DGL activity below a threshold level plays a permissive role in the enhancement of cue-induced cocaine seeking.

However, a number of lines of evidence argue against this possibility. First, mGlu5/CB1R-dependent synaptic depression has been linked to the promotion of reward seeking in mice with constitutive knockdown of mGlu5 in $D_{1}$ receptor-expressing MSNs. These mice do not express mGlu5-dependent synaptic depression or demonstrate cue-induced reinstatement of cocaine or saccharin seeking; however, after 2-AG elevation with monoacylglycerol lipase (MAGL) inhibition, reinstatement of saccharin seeking is restored (Novak et al., 2010; Bilbao et al., 2020). Furthermore, it was found that DGL and MAGL 
were dysregulated after prolonged abstinence $(30 \mathrm{~d})$ from cocaine self-administration, and that intra-NAc administration of a DGL inhibitor at this withdrawal time reduced cue-induced cocaine craving, while inhibition of MAGL (to increase 2-AG levels) had the opposite effect (Mitra et al., 2021). We note that DGL levels were increased at WD30 in this prior study (Mitra et al., 2021), in contrast to the lack of change reported here. This is most likely because of the fact that Mitra et al. (2021) measured DGL in NAc shell, whereas we analyzed NAc core; there were also significant differences in the cocaine self-administration regimen. While the work cited above focused on synaptic depression expressed presynaptically via CB1R stimulation, other studies link mGlu5-dependent reinstatement of cocaine seeking to postsynaptically expressed LTD mediated via AMPAR internalization (Schmidt et al., 2013; Benneyworth et al., 2019).

Additional evidence against a causal relationship between loss of mGlu5/CB1R-dependent synaptic depression and elevation of cue-induced drug craving comes from studies on the incubation of methamphetamine craving. Dihydroxyphenylglycine-induced, mGlu5-dependent synaptic depression in the NAc core was lost during the first week of abstinence from extended-access methamphetamine self-administration, which corresponds to the rising phase of incubation of methamphetamine craving, but at later withdrawal times this synaptic depression was restored whereas craving remained at high "incubated" levels (Murray et al., 2021). These results argue against a role for mGlu5/CB1R-dependent synaptic depression in maintaining incubated craving for methamphetamine. It is also interesting to note that associations between CaMKII and DGL were unaltered during the first week of methamphetamine withdrawal when mGlu5/CB1R-dependent synaptic depression was lost (Murray et al., 2021), in contrast to the present results with cocaine. This adds to mechanistic distinctions between incubation of cocaine and methamphetamine craving, although commonalities also exist (Murray et al., 2019).

Overall, these results argue that synaptic depression can promote (Novak et al., 2010; Bilbao et al., 2020; Mitra et al., 2021) or be dissociated from (Murray et al., 2021) drug or natural reward seeking. Thus, the functional significance of the observed reduction in DGL activity observed after prolonged cocaine withdrawal remains unclear. Likewise, no consensus has emerged from work that has tested the effect of manipulation of eCB signaling on seeking for cocaine and other drugs of abuse. While reducing endocannabinoid signaling through negative allosteric modulation has shown therapeutic promise, so too has enhancement of endocannabinoid signaling through the inhibition of endocannabinoid degradation (Galaj and Xi, 2019). The complex nature of effects observed after pharmacological targeting of CB1Rs is likely to reflect their widespread expression (e.g., they are expressed not only on glutamate terminals but also on GABA terminals throughout the brain (Augustin and Lovinger, 2018). Furthermore, within the NAc, in addition to mediating synaptic depression onto MSNs, endocannabinoids also mediate synaptic depression onto parvalbumin-containing interneurons that regulate MSN activity (Manz et al., 2020) and contribute to the modulation of dopamine release (Mateo et al., 2017).

\section{Conclusion}

The loss of mGlu5/CB1R-dependent synaptic depression in the NAc core after incubation of cocaine craving is likely attributable to multiple postsynaptic mechanisms, including reduced surface expression of mGlu5 and reduced mGlu5-Homer interactions (Loweth et al., 2014) and, as shown here, a reduction in DGL activity that may result from increased CaMKII-DGL association. Although our findings and related work in the literature suggest that the loss of mGlu5/CB1R-dependent synaptic transmission is unlikely to be a driver of the incubation of cocaine craving, it is expected that loss of a major form of synaptic plasticity would have significant consequences for NAc function. Future studies should continue to explore this problem.

\section{References}

Ade KK, Lovinger DM (2007) Anandamide regulates postnatal development of long-term synaptic plasticity in the rat dorsolateral striatum. J Neurosci 27:2403-2409.

Anderson SM, Famous KR, Sadri-Vakili G, Kumaresan V, Schmidt HD, Bass CE, Terwilliger EF, Cha JH, Pierce RC (2008) CaMKII: a biochemical bridge linking accumbens dopamine and glutamate systems in cocaine seeking. Nat Neurosci 11:344-353.

Araque A, Castillo PE, Manzoni OJ, Tonini R (2017) Synaptic functions of endocannabinoid signaling in health and disease. Neuropharmacology 124:13-24.

Augustin SM, Lovinger DM (2018) Functional relevance of endocannabinoid-dependent synaptic plasticity in the central nervous system. ACS Chem Neurosci 9:2146-2161.

Bayer KU, Schulman H (2019) CaM Kinase: still Inspiring at 40. Neuron 103:380-394.

Benneyworth MA, Hearing MC, Asp AJ, Madayag A, Ingebretson AE, Schmidt CE, Silvis KA, Larson EB, Ebner SR, Thomas MJ (2019) Synaptic depotentiation and mGluR5 activity in the nucleus accumbens drive cocaine-primed reinstatement of place preference. J Neurosci 39:4785-4796.

Bilbao A, Neuhofer D, Sepers M, Wei SP, Eisenhardt M, Hertle S, Lassalle O, Ramos-Uriarte A, Puente N, Lerner R, Thomazeau A, Grandes P, Lutz B, Manzoni OJ, Spanagel R (2020) Endocannabinoid LTD in accumbal D1 neurons mediates reward-seeking behavior. iScience 23:100951.

Boudreau AC, Wolf ME (2005) Behavioral sensitization to cocaine is associated with increased AMPA receptor surface expression in the nucleus accumbens. J Neurosci 25:9144-9151.

Caffino L, Cassina C, Giannotti G, Orrù A, Moro F, Di Clemente A, Racagni G, Fumagalli F, Cervo L (2014) Short-term abstinence from cocaine self-administration, but not passive cocaine infusion, elevates $\alpha$ CaMKII autophosphorylation in the rat nucleus accumbens and medial prefrontal cortex. Int $\mathrm{J}$ Neuropsychopharmacol 17:323-329.

Carr KD (2020) Homeostatic regulation of reward via synaptic insertion of calcium-permeable AMPA receptors in nucleus accumbens. Physiol Behav 219:112850.

Chen L, Lau AG, Sarti F (2014) Synaptic retinoic acid signaling and homeostatic synaptic plasticity. Neuropharmacology 78:3-12.

Conrad KL, Tseng KY, Uejima JL, Reimers JM, Heng LJ, Shaham Y, Marinelli M, Wolf ME (2008) Formation of accumbens GluR2-lacking AMPA receptors mediates incubation of cocaine craving. Nature 454:118-121.

Ferrario CR, Loweth JA, Milovanovic M, Ford KA, Galiñanes GL, Heng LJ, Tseng KY, Wolf ME (2011) Alterations in AMPA receptor subunits and TARPs in the rat nucleus accumbens related to the 
formation of $\mathrm{Ca}^{2+}$-permeable AMPA receptors during the incubation of cocaine craving. Neuropharmacology 61:1141-1151.

Folkes OM, Báldi R, Kondev V, Marcus DJ, Hartley ND, Turner BD, Ayers JK, Baechle JJ, Misra MP, Altemus M, Grueter CA, Grueter BA, Patel S (2020) An endocannabinoid-regulated basolateral amygdala-nucleus accumbens circuit modulates sociability. J Clin Invest 130:1728-1742.

Fourgeaud L, Mato S, Bouchet D, Hémar A, Worley PF, Manzoni OJ (2004) A single in vivo exposure to cocaine abolishes endocannabinoid-mediated long-term depression in the nucleus accumbens. J Neurosci 24:6939-6945.

Galaj E, Xi ZX (2019) Potential of cannabinoid receptor ligands as treatment for substance use disorders. CNS Drugs 33:1001-1030.

Groth RD, Lindskog M, Thiagarajan TC, Li L, Tsien RW (2011) Beta $\mathrm{Ca} 2+/ \mathrm{CaM}$-dependent kinase type II triggers upregulation of GluA1 to coordinate adaptation to synaptic inactivity in hippocampal neurons. Proc Natl Acad Sci U S A 108:828-833.

Grueter BA, Brasnjo G, Malenka RC (2010) Postsynaptic TRPV1 triggers cell type-specific long-term depression in the nucleus accumbens. Nat Neurosci 13:1519-1525.

Guillem K, Ahmed SH, Peoples LL (2014) Escalation of cocaine intake and incubation of cocaine seeking are correlated with dissociable neuronal processes in different accumbens subregions. Biol Psychiatry 76:31-39.

Hell JW (2014) CaMKII: claiming center stage in postsynaptic function and organization. Neuron 81:249-265.

Hollingsworth EB, McNeal ET, Burton JL, Williams RJ, Daly JW, Creveling CR (1985) Biochemical characterization of a filtered synaptoneurosome preparation from guinea pig cerebral cortex: cyclic adenosine $3^{\prime}: 5^{\prime}$-monophosphate-generating systems, receptors, and enzymes. J Neurosci 5:2240-2253.

Huang CC, Yeh CM, Wu MY, Chang AY, Chan JY, Chan SH, Hsu KS (2011) Cocaine withdrawal impairs metabotropic glutamate receptor-dependent long-term depression in the nucleus accumbens. $J$ Neurosci 31:4194-4203.

Jingami H, Nakanishi S, Morikawa K (2003) Structure of the metabotropic glutamate receptor. Curr Opin Neurobiol 13:271-278.

Johnston M, Bhatt SR, Sikka S, Mercier RW, West JM, Makriyannis A, Gatley SJ, Duclos RI Jr (2012) Assay and inhibition of diacylglycerol lipase activity. Bioorg Med Chem Lett 22:4585-4592.

Jung KM, Astarita G, Zhu C, Wallace M, Mackie K, Piomelli D (2007) A key role for diacylglycerol lipase-alpha in metabotropic glutamate receptor-dependent endocannabinoid mobilization. Mol Pharmacol 72:612-621.

Katona I, Urbán GM, Wallace M, Ledent C, Jung KM, Piomelli D, Mackie K, Freund TF (2006) Molecular composition of the endocannabinoid system at glutamatergic synapses. J Neurosci 26:5628-5637.

Keimpema E, Barabas K, Morozov YM, Tortoriello G, Torii M, Cameron G, Yanagawa Y, Watanabe M, Mackie K, Harkany T (2010) Differential subcellular recruitment of monoacylglycerol lipase generates spatial specificity of 2-arachidonoyl glycerol signaling during axonal pathfinding. J Neurosci 30:13992-14007.

Kerstetter KA, Aguilar VR, Parrish AB, Kippin TE (2008) Protracted timedependent increases in cocaine-seeking behavior during cocaine withdrawal in female relative to male rats. Psychopharmacology (Berl) 198:63-75.

Lee BR, Ma YY, Huang YH, Wang X, Otaka M, Ishikawa M, Neumann PA, Graziane NM, Brown TE, Suska A, Guo C, Lobo MK, Sesack SR, Wolf ME, Nestler EJ, Shaham Y, Schlüter OM, Dong Y (2013) Maturation of silent synapses in amygdala-accumbens projection contributes to incubation of cocaine craving. Nat Neurosci 16:1644-1651.

Li X, Caprioli D, Marchant NJ (2015) Recent updates on incubation of drug craving: a mini-review. Addict Biol 20:872-876.

Lisman J, Schulman H, Cline H (2002) The molecular basis of CaMKII function in synaptic and behavioural memory. Nat Rev Neurosci 3:175-190.

Lisman J, Yasuda R, Raghavachari S (2012) Mechanisms of CaMKII action in long-term potentiation. Nat Rev Neurosci 13:169-182.
Loweth JA, Baker LK, Guptaa T, Guillory AM, Vezina P (2008) Inhibition of CaMKII in the nucleus accumbens shell decreases enhanced amphetamine intake in sensitized rats. Neurosci Lett 444:157-160.

Loweth JA, Singer BF, Baker LK, Wilke G, Inamine H, Bubula N, Alexander JK, Carlezon WA Jr, Neve RL, Vezina P (2010) Transient overexpression of $\alpha-\mathrm{Ca}^{2+} /$ calmodulin-dependent protein kinase II in the nucleus accumbens shell enhances behavioral responding to amphetamine. J Neurosci 30:939-949.

Loweth JA, Li D, Cortright JJ, Wilke G, Jeyifous O, Neve RL, Bayer KU, Vezina P (2013) Persistent reversal of enhanced amphetamine intake by transient CaMKII inhibition. J Neurosci 33:1411-1416.

Loweth JA, Scheyer AF, Milovanovic M, LaCrosse AL, Flores-Barrera E, Werner CT, Li X, Ford KA, Le T, Olive MF, Szumlinski KK, Tseng KY, Wolf ME (2014) Synaptic depression via mGluR1 positive allosteric modulation suppresses cue-induced cocaine craving. Nat Neurosci 17:73-80.

Loweth JA, Reimers JM, Caccamise A, Stefanik MT, Woo KKY, Chauhan NM, Werner CT, Wolf ME (2019) mGlu1 tonically regulates levels of calcium-permeable AMPA receptors in cultured nucleus accumbens neurons through retinoic acid signaling and protein translation. Eur J Neurosci 50:2590-2601.

Lu L, Grimm JW, Hope BT, Shaham Y (2004) Incubation of cocaine craving after withdrawal: a review of preclinical data. Neuropharmacology 47 [Suppl 1]:214-226.

Lüscher C (2016) The emergence of a circuit model for addiction. Annu Rev Neurosci 39:257-276.

Ma YY, Lee BR, Wang X, Guo C, Liu L, Cui R, Lan Y, BalcitaPedicino JJ, Wolf ME, Sesack SR, Shaham Y, Schlüter OM, Huang YH, Dong Y (2014) Bidirectional modulation of incubation of cocaine craving by silent synapse-based remodeling of prefrontal cortex to accumbens projections. Neuron 83:1453-1467.

Manz KM, Ghose D, Turner BD, Taylor A, Becker J, Grueter CA, Grueter BA (2020) Calcium-permeable AMPA receptors promote endocannabinoid signaling at parvalbumin interneuron synapses in the nucleus accumbens core. Cell Rep 32:107971.

Mateo Y, Johnson KA, Covey DP, Atwood BK, Wang HL, Zhang S, Gildish I, Cachope R, Bellocchio L, Guzmán M, Morales M, Cheer JF, Lovinger DM (2017) Endocannabinoid actions on cortical terminals orchestrate local modulation of dopamine release in the nucleus accumbens. Neuron 96:1112-1126.e5.

McCutcheon JE, Loweth JA, Ford KA, Marinelli M, Wolf ME, Tseng KY (2011) Group I mGluR activation reverses cocaine-induced accumulation of calcium-permeable AMPA receptors in nucleus accumbens synapses via a protein kinase $\mathrm{C}$-dependent mechanism. J Neurosci 31:14536-14541.

Meredith GE, Baldo BA, Andrezjewski ME, Kelley AE (2008) The structural basis for mapping behavior onto the ventral striatum and its subdivisions. Brain Struct Funct 213:17-27.

Mitra S, Gobira PH, Werner CT, Martin JA, lida M, Thomas SA, Erias K, Miracle S, Lafargue C, An C, Dietz DM (2021) A role for the endocannabinoid enzymes monoacylglycerol and diacylglycerol lipases in cue-induced cocaine craving following prolonged abstinence. Addict Biol 26:e13007.

Most D, Ferguson L, Blednov Y, Mayfield RD, Harris RA (2015) The synaptoneurosome transcriptome: a model for profiling the emolecular effects of alcohol. Pharmacogenomics J 15:177-188.

Murray $\mathrm{CH}$, Loweth JA, Milovanovic M, Stefanik MT, Caccamise AJ, Dolubizno H, Funke JR, Foster Olive M, Wolf ME (2019) AMPA receptor and metabotropic glutamate receptor 1 adaptations in the nucleus accumbens core during incubation of methamphetamine craving. Neuropsychopharmacology 44:1534-1541.

Murray $\mathrm{CH}$, Christian DT, Milovanovic M, Loweth JA, Hwang EK, Caccamise AJ, Funke JR, Wolf ME (2021) mGlu5 function in the nucleus accumbens core during the incubation of methamphetamine craving. Neuropharmacology 186:108452.

Nassal D, Gratz D, Hund TJ (2020) Challenges and opportunities for therapeutic targeting of calmodulin kinase II in heart. Front Pharmacol 11:35. 
Nicolas C, Russell TI, Pierce AF, Maldera S, Holley A, You ZB, McCarthy MM, Shaham Y, Ikemoto S (2019) Incubation of cocaine craving after intermittent-access self-administration: sex differences and estrous cycle. Biol Psychiatry 85:915-924.

Novak M, Halbout B, O'Connor EC, Rodriguez Parkitna J, Su T, Chai M, Crombag HS, Bilbao A, Spanagel R, Stephens DN, Schütz G, Engblom D (2010) Incentive learning underlying cocaine-seeking requires mGluR5 receptors located on dopamine $D_{1}$ receptor-expressing neurons. J Neurosci 30:11973-11982.

O'Brien CP (2005) Anticraving medications for relapse prevention: a possible new class of psychoactive medications. Am J Psychiatry 162:1423-1431.

Ohno-Shosaku T, Kano M (2014) Endocannabinoid-mediated retrograde modulation of synaptic transmission. Curr Opin Neurobiol 29:1-8.

Park H, Rhee J, Lee S, Chung C (2017) Selectively impaired endocannabinoid-dependent long-term depression in the lateral habenula in an animal model of depression. Cell Rep 20:289-296.

Parvaz MA, Moeller SJ, Goldstein RZ (2016) Incubation of cue-induced craving in adults addicted to cocaine measured by electroencephalography. JAMA Psychiatry 73:1127-1134.

Pascoli V, Terrier J, Espallergues J, Valjent E, O'Connor EC, Lüscher C (2014) Contrasting forms of cocaine-evoked plasticity control components of relapse. Nature 509:459-464.

Pickens CL, Airavaara M, Theberge F, Fanous S, Hope BT, Shaham $Y$ (2011) Neurobiology of the incubation of drug craving. Trends Neurosci 34:411-420.

Piomelli D (2014) More surprises lying ahead. The endocannabinoids keep us guessing. Neuropharmacology 76:228-234.

Quinlan EM, Olstein DH, Bear MF (1999) Bidirectional, experiencedependent regulation of $\mathrm{N}$-methyl-D-aspartate receptor subunit composition in the rat visual cortex during postnatal development. Proc Natl Acad Sci U S A 96:12876-12880.

Robbe D, Alonso G, Duchamp F, Bockaert J, Manzoni OJ (2001) Localization and mechanisms of action of cannabinoid receptors at the glutamatergic synapses of the mouse nucleus accumbens. J Neurosci 21:109-116.

Robbe D, Kopf M, Remaury A, Bockaert J, Manzoni OJ (2002) Endogenous cannabinoids mediate long-term synaptic depression in the nucleus accumbens. Proc Natl Acad Sci U S A 99:83848388.

Roloff AM, Anderson GR, Martemyanov KA, Thayer SA (2010) Homer 1a gates the induction mechanism for endocannabinoid-mediated synaptic plasticity. J Neurosci 30:3072-3081.

Ronesi J, Gerdeman GL, Lovinger DM (2004) Disruption of endocannabinoid release and striatal long-term depression by postsynaptic blockade of endocannabinoid membrane transport. J Neurosci 24:1673-1679.

Scheyer AF, Wolf ME, Tseng KY (2014) A protein synthesis-dependent mechanism sustains calcium-permeable AMPA receptor transmission in nucleus accumbens synapses during withdrawal from cocaine self-administration. J Neurosci 34:3095-3100.

Scheyer AF, Christian DT, Wolf ME, Tseng KY (2018) Emergence of endocytosis-dependent mGlu1 LTD at nucleus accumbens synapses after withdrawal from cocaine self-administration. Front Synaptic Neurosci 10:36.
Schmidt HD, Schassburger RL, Guercio LA, Pierce RC (2013) Stimulation of mGluR5 in the accumbens shell promotes cocaine seeking by activating PKC gamma. J Neurosci 33:14160-14169.

Scofield MD, Heinsbroek JA, Gipson CD, Kupchik YM, Spencer S, Smith AC, Roberts-Wolfe D, Kalivas PW (2016) The nucleus accumbens: mechanisms of addiction across drug classes reflect the importance of glutamate homeostasis. Pharmacol Rev 68:816-871.

Sesack SR, Grace AA (2010) Cortico-Basal Ganglia reward network: microcircuitry. Neuropsychopharmacology 35:27-47.

Shonesy BC, Wang X, Rose KL, Ramikie TS, Cavener VS, Rentz T, Baucum AJ, Jalan-Sakrikar N, Mackie K, Winder DG, Patel S, Colbran RJ (2013) CaMKII regulates diacylglycerol lipase- $\alpha$ and striatal endocannabinoid signaling. Nat Neurosci 16:456-463.

Sun X, Wolf ME (2009) Nucleus accumbens neurons exhibit synaptic scaling that is occluded by repeated dopamine pre-exposure. Eur J Neurosci 30:539-550.

Szumlinski KK, Ary AW, Lominac KD (2008) Homers regulate druginduced neuroplasticity: implications for addiction. Biochem Pharmacol 75:112-133.

Terrier J, Lüscher C, Pascoli V (2016) Cell-type specific insertion of GluA2lacking AMPARs with cocaine exposure leading to sensitization, cue-induced seeking, and incubation of craving. Neuropsychopharmacology 41:1779-1789.

Thiagarajan TC, Piedras-Renteria ES, Tsien RW (2002) alpha- and betaCaMKII. Inverse regulation by neuronal activity and opposing effects on synaptic strength. Neuron 36:1103-1114.

Thiagarajan TC, Lindskog M, Tsien RW (2005) Adaptation to synaptic inactivity in hippocampal neurons. Neuron 47:725-737.

Wang J, Ishikawa M, Yang Y, Otaka M, Kim JY, Gardner GR, Stefanik MT, Milovanovic M, Huang YH, Hell JW, Wolf ME, Schlüter OM, Dong Y (2018) Cascades of homeostatic dysregulation promote incubation of cocaine craving. J Neurosci 38:43164328.

Wang L, Lv Z, Hu Z, Sheng J, Hui B, Sun J, Ma L (2010) Chronic cocaine-induced $\mathrm{H} 3$ acetylation and transcriptional activation of CaMKIlalpha in the nucleus accumbens is critical for motivation for drug reinforcement. Neuropsychopharmacology 35:913-928.

Werner CT, Stefanik MT, Milovanovic M, Caccamise A, Wolf ME (2018) Protein translation in the nucleus accumbens is dysregulated during cocaine withdrawal and required for expression of incubation of cocaine craving. J Neurosci 38:2683-2697.

Wolf ME (2016) Synaptic mechanisms underlying persistent cocaine craving. Nat Rev Neurosci 17:351-365.

Wolf ME, Tseng KY (2012) Calcium-permeable AMPA receptors in the VTA and nucleus accumbens after cocaine exposure: when, how, and why? Front Mol Neurosci 5:72.

Workman ER, Haddick PC, Bush K, Dilly GA, Niere F, Zemelman BV, Raab-Graham KF (2015) Rapid antidepressants stimulate the decoupling of GABA(B) receptors from GIRK/Kir3 channels through increased protein stability of 14-3-3 $\eta$. Mol Psychiatry 20:298-310.

Wright WJ, Dong Y (2020) Psychostimulant-induced adaptations in nucleus accumbens glutamatergic transmission. Cold Spring Harb Perspect Med 10:

Zlebnik NE, Cheer JF (2016) Drug-induced alterations of endocannabinoid-mediated plasticity in brain reward regions. J Neurosci 36:10230-10238. 